Supplement of Atmos. Chem. Phys. Discuss., 15, 22097-22139, 2015

http://www.atmos-chem-phys-discuss.net/15/22097/2015/

doi:10.5194/acpd-15-22097-2015-supplement

(C) Author(s) 2015. CC Attribution 3.0 License.

(c) (i)

\title{
Detailed budget analysis of HONO in central London reveals a missing daytime source
}

\section{J. D. Lee et al.}

Correspondence to: J. D. Lee (james.lee@york.ac.uk)

The copyright of individual parts of the supplement might differ from the CC-BY 3.0 licence. 
Figure S1: Relationships between observed variables (and their products) and the product of jHONO and the modelled missing HONO (using the model containing all additional sources). The relationships between the normalised products of observed variables shown are those for which the correlation coefficient was higher than that between missing HONO and each of the individual components in the product. Full details are given in the main text, with the correlation
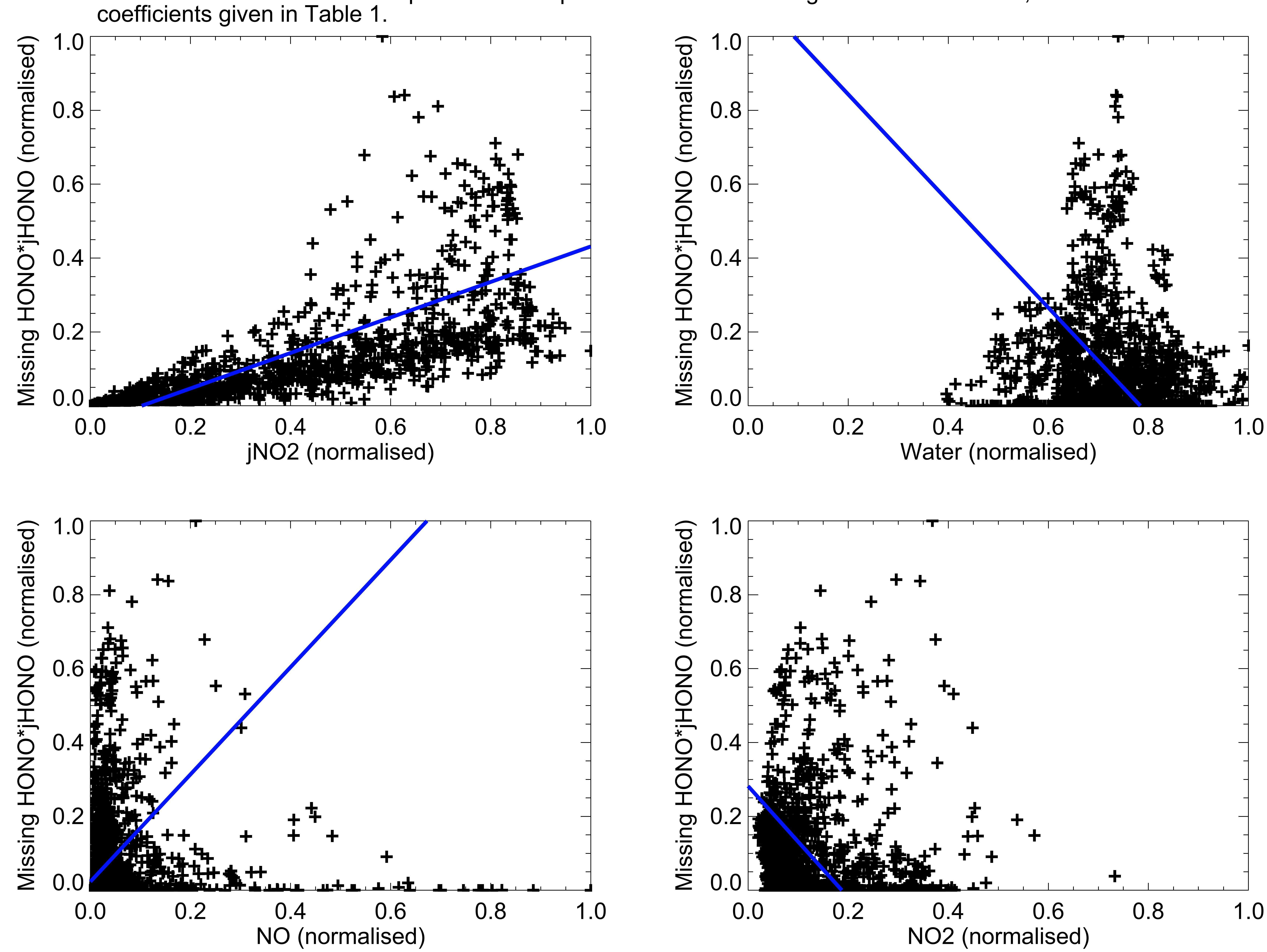

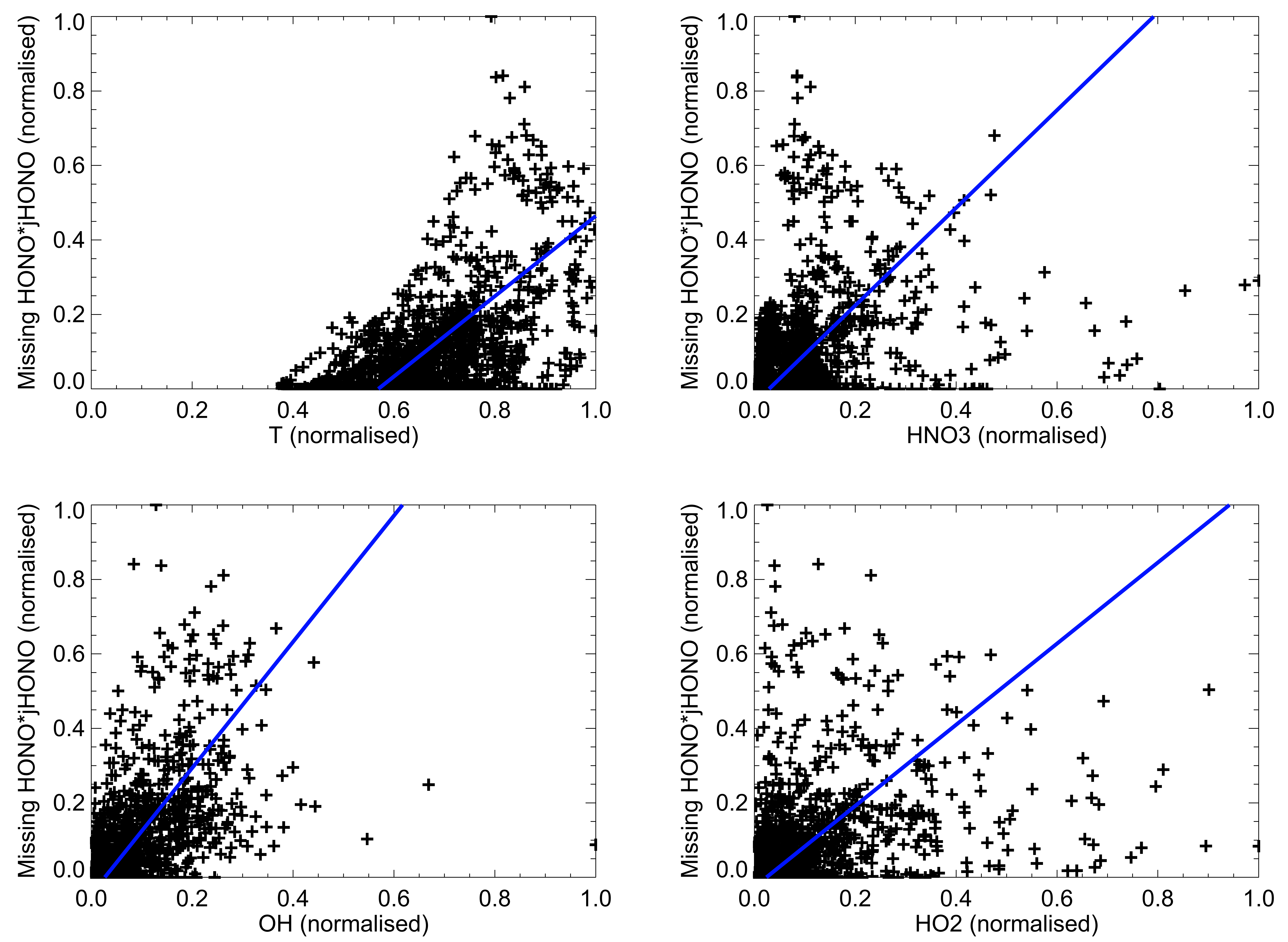

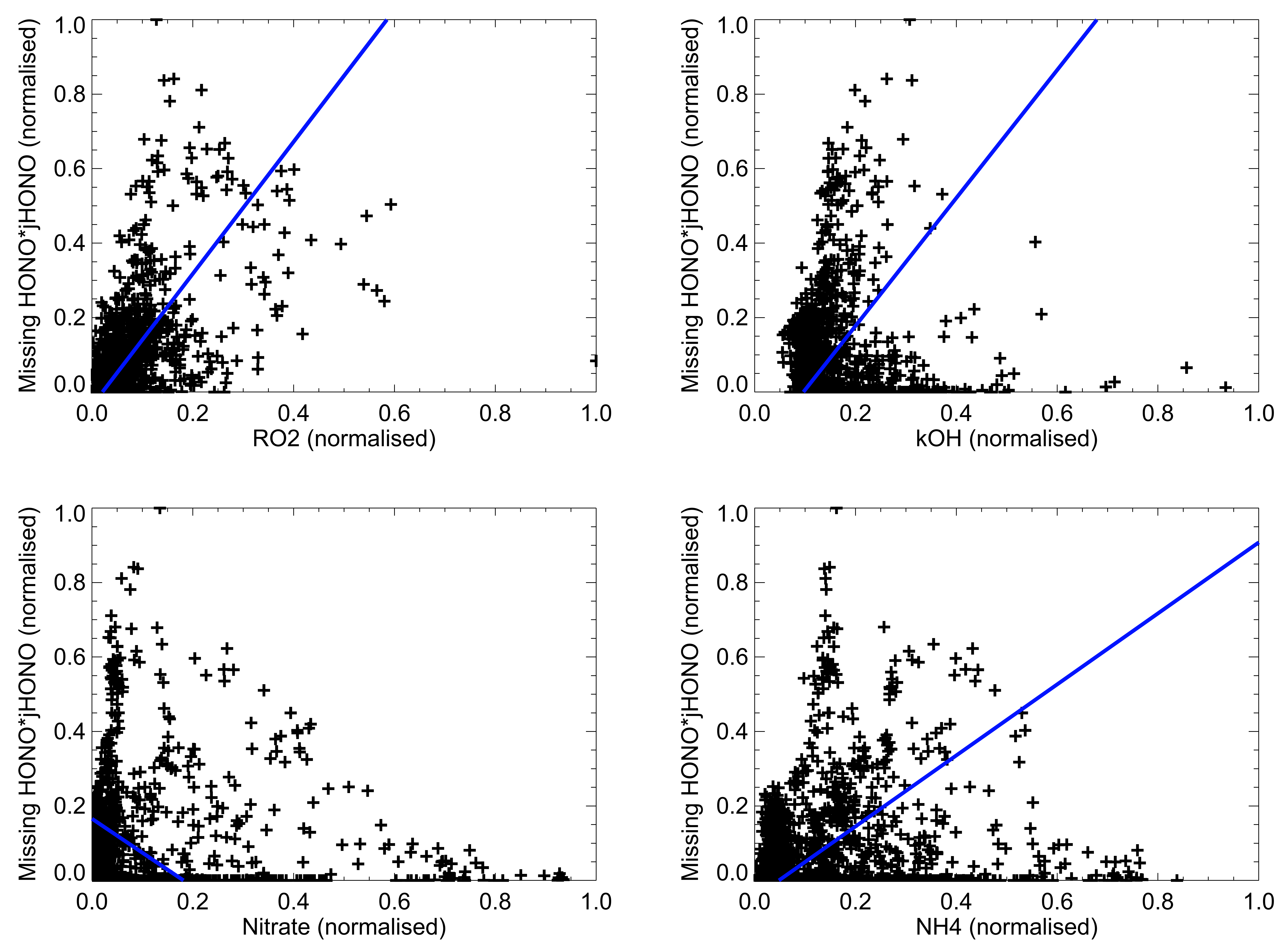

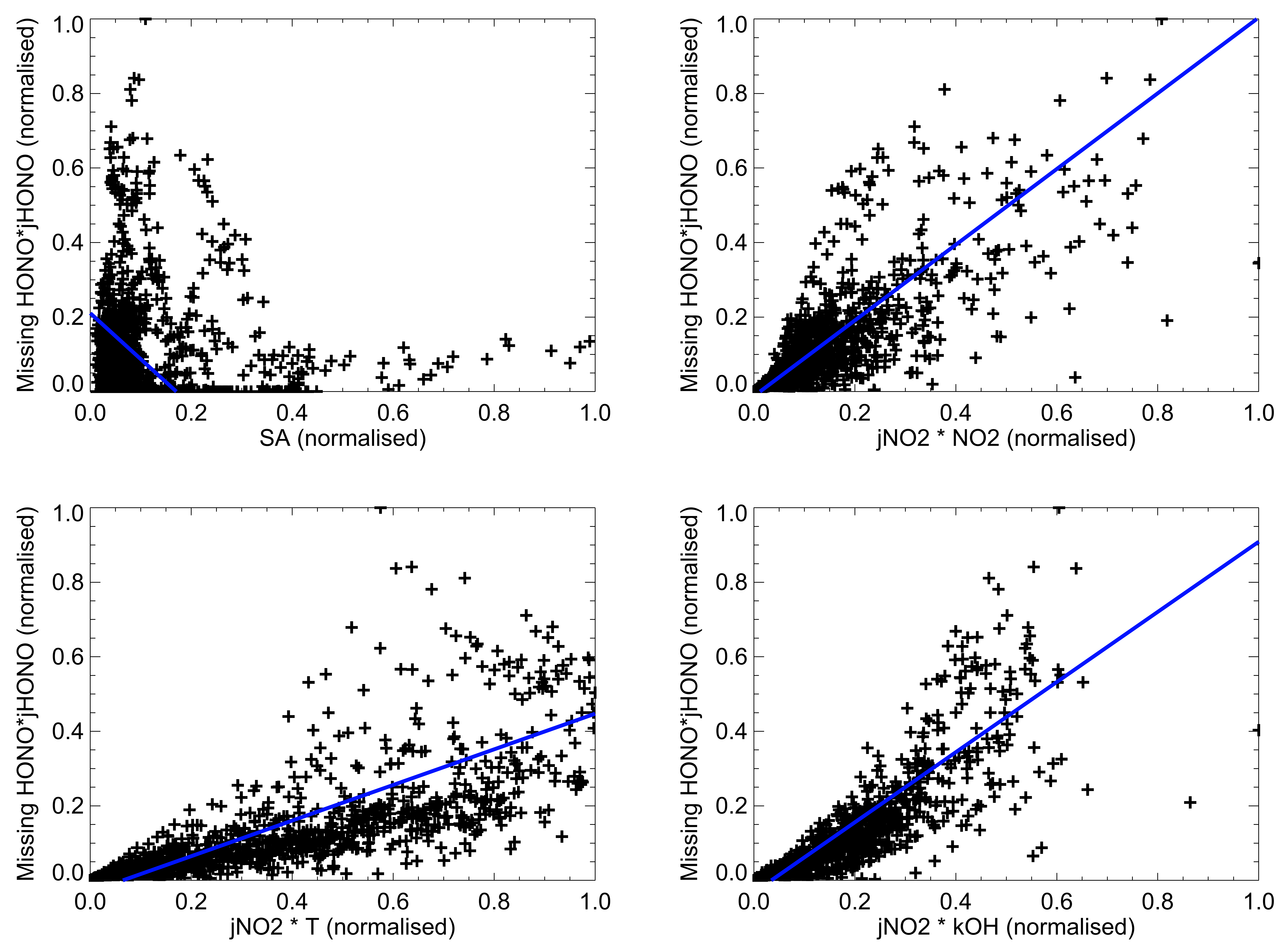

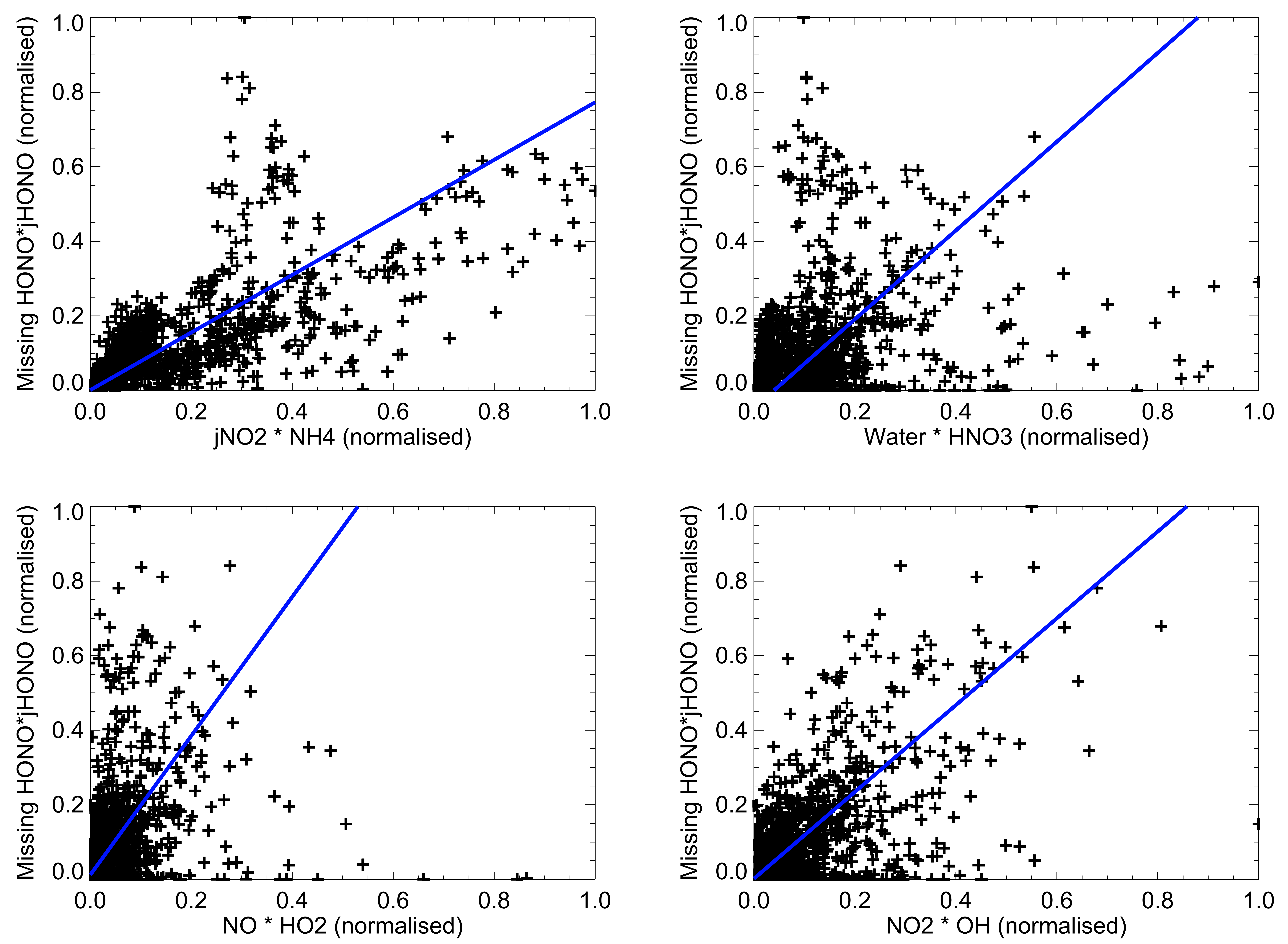

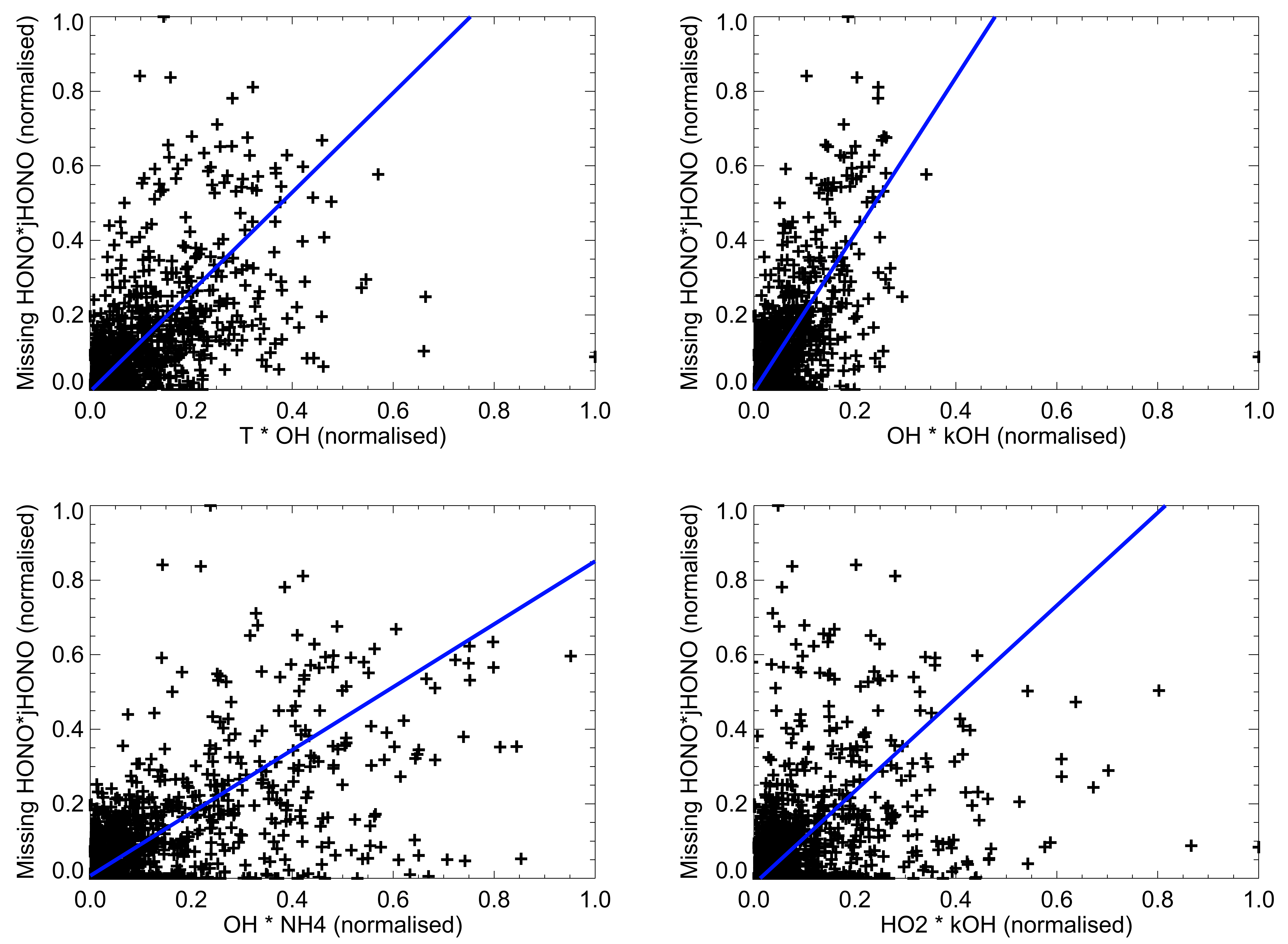